\title{
Application of loT and Countermeasure in Agriculture of Shandong Province, China
}

\author{
Li Guangzhong \\ Department of Computer Science and Technology, Shandong Agricultural University, Taian City, China \\ Email address: \\ gzhl@sdau.edu.cn \\ To cite this article: \\ Li Guangzhong. Application of IoT and Countermeasure in Agriculture of Shandong Province, China. Internet of Things and Cloud \\ Computing. Vol. 8, No. 1, 2020, pp. 8-11. doi: 10.11648/j.iotcc.20200801.12
}

Received: April 1, 2020; Accepted: April 21, 2020; Published: April 28, 2020

\begin{abstract}
As a major agricultural province in China, Shandong Province has always played an important role. At the same time, it is also closely related to the strong support of science and technology. As a new technology, the Internet of things (IoT) has made positive contributions. Agricultural IoT is a mode that uses information technology, wireless communication technology and radio frequency automatic identification technology to share the identified agricultural information to the network. The application of agricultural IoT is a major change in agricultural development, which provides convenient conditions for the development of agriculture, provides a favorable environment for the agricultural products, promotes the transformation of agricultural technology, realizes the informatization of agricultural production, improves the efficiency of rural land, integrates agricultural resources and provides a foundation for food safety. In this paper, the application of IoT in the field of agriculture in Shandong Province is described from two practical cases. One is about how to use wireless sensor network technology to transmit data in the big data platform based on the Bohai granary project. The other describes how to use IoT for food quality and safety traceability. It takes pigs as the research object, runs through all links of the whole industrial chain of pig breeding, breeding, slaughtering, processing, logistics and sales, collects the data of the whole industrial chain with the help of IoT, and realizes the information tracking and traceability of the whole industrial chain. At the end of the paper, it discusses the countermeasures.
\end{abstract}

Keywords: IoT, WSN, The Quality and Safety Traceability System

\section{Introduction}

Agriculture, as the dominant industry in Shandong Province, plays an important role in China. Several indicators of the agriculture have always been at the forefront of the country. The total output value of agriculture, forestry, animal husbandry, and fishery, the Value-added of Primary Industry and the export of agricultural products has always been the first in the country. Grain ranks the third, cotton and oil plants rank the second, and the total output of vegetables, fruits, meat, eggs, and milk, and aquatic products rank the first. According to statistics, Shandong Province, with $6 \%$ of the country's arable land and $1 \%$ of the country's water resources, has produced $8 \%$ of the country's grain, $13 \%$ of the country's vegetables and $10 \%$ of the country's meat, eggs and milk, making a positive contribution to the country [1].

The strong joint force of agricultural science and technology innovation in the whole province plays a leading and supporting role in the development of agriculture. Using IoT technology in agriculture forms IoT in agriculture, The Agricultural IoT connects all links of agricultural production through the network to realize the real-time monitoring and effective control of the whole agricultural production process.

Here are two examples to illustrate the application of IoT in agricultural production in Shandong Province, China.

\section{Application of IoT in Bohai Granary Science and Technology Demonstration Project}

\subsection{Big Data Platform of Bohai Granary Science and Technology Project}

In 2013, the state began to implement the "Bohai granary 
science and technology demonstration project", a major national science and technology support program.

The project aims at the problems of 40 million $\mathrm{mu}$ of medium and low yield fields and 10 million mu of salt alkali wasteland in the plain around the Bohai Sea, such as lack of water resources, poor soil and salt alkali restricting grain production. It focuses on breaking through technologies such as soil, fertilizer, water, and seed, and establishes a grain production demonstration area in the local area. The goal is to increase grain by 3 billion $\mathrm{kg}$ by 2017 and 5 billion $\mathrm{kg}$ by 2020 [2].

Researchers design a big data platform for this project. The platform system mainly includes four modules: data collection, mining analysis, monitoring, and early warning, and decision-making service. Among them, the data acquisition module, through the scientific assembly of various sensors such as meteorology, seedlings, soil, and groundwater, forms a ground air integrated sensor cluster, constructs an intelligent sensing system for crop growth process environmental information, collects and transmits all kinds of data in real- time, and provides all-weather and three-dimensional data support for subsequent data analysis, monitoring and early warning, and decision-making services [3].

The agricultural big data platform of Bohai granary has completed the functions of influencing factors analysis of grain production, data collection and transmission, data storage, and partial data analysis and application. From bottom to top, the agricultural data platform structure of Bohai granary is divided into three layers: data acquisition layer, data storage layer, and data application layer [4].

\subsection{The Wireless Data Acquisition System}

There are many ways of data acquisition. The main methods of data acquisition are on-site manual collection and real-time collection of IoT. Using the self-developed real-time data acquisition base station of IoT, the real-time and accurate acquisition of key factors of meteorological information (wind speed and direction, air temperature and humidity, light intensity, rainfall, evaporation), soil information (salt, soil pH value, water level, water salinity, soil temperature, and humidity) and crop growth (Leaf area index, dry matter accumulation, nitrogen content, nitrogen accumulation, and chlorophyll content) is realized [5 7].

Data transmission uses ZigBee wireless sensor network technology [8]. ZigBee sensor network node is composed of four modules: processor, radio frequency transmission, sensor, and power supply. Figure 1 shows the relationship between node modules. The processor module completes the functions of network node equipment control, task scheduling, logical calculation, coordination, etc; The radio frequency transceiver module completes data transmission and frequency selection among network nodes. The sensor module completes the sampling and conversion of external sensor signals; The power supply module provides the necessary power for the network sensor nodes to maintain the operation of the network [9].

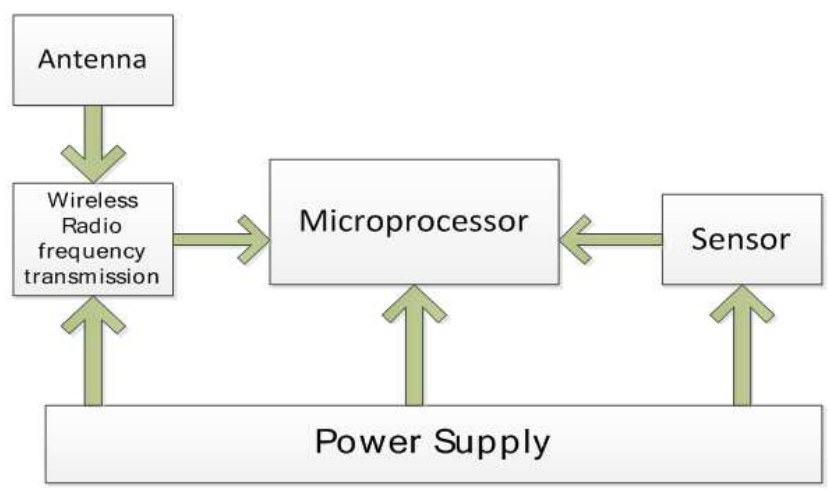

Figure 1. Relationship between node modules.

In the hardware design of the ZigBee node, the radio frequency transceiver module uses the CC2430 chip of TI company, and the main control chip uses the MSP430 chip of TI company [10]. Each ZigBee node is arranged in the monitoring area according to the requirements through ZigBee. The whole ZigBee wireless network system collects and uploads the data in the monitoring area to the monitoring host, and the monitoring host analyzes and collects the data [11].

MSP430 adopts the master mode, CC2430 adopts the slave mode. Receive and transmit data uses four pins of SFD, FIFO, FIFOP, and CCA; the processor exchanges data and sends commands with CC2430 through the SPI interface. The processor accesses CC2430 internal memory through the SPI interface. During the access process, CC2430 is the slave device of the SPI interface, which receives a clock signal from the processor and performs input/output operation under the control of the processor.

\subsection{Application Results}

There are three areas around the Bohai Sea in the saline-alkali land of Shandong Province. The platform has completed 72 data collection stations. The meteorological, seedling, soil, and groundwater data of 27 demonstration sites in the Shandong project area of "Bohai granary" were collected, processed, and analyzed, which effectively solved the problems of real-time data collection in the field of grain production. After research and development, testing, adjustment, optimization, and demonstration application, the platform now has the characteristics of massive data source diversity, integration of historical and real-time data, multi-factor comprehensive analysis, and decision-making. It has been applied to the grain production management and decision-making process of typical plots in the Shandong project area of Bohai granary, guiding the grain production in the project area.

\section{Application of IoT in the Safety Traceability of Pig Industry Chain}

IoT is a kind of network that connects any object with the Internet through RFID, infrared sensor, global positioning system, laser scanner, and other information sensing 
equipment to exchange and communicate information, to realize intelligent identification, positioning, tracking, monitoring, and management [12].

The Traceability System about Agricultural Products Quality and Safety is to realize digital management of the whole industrial chain of products from breeding, transportation, slaughtering, segmentation, storage, processing to marketing [13].

Achieve precise of production process and supervision, prevent cross mixing of products from different sources, Keep complete and detailed personal information of products, keep complete data, test reports, and relevant certificates, to facilitate downstream producers and consumers to query and check at any time, Especially in the case of food safety incidents, find out the cause of the accident quickly, make control decisions immediately, minimize the possible losses and hazards, and reduce unnecessary panic [14].

This application takes the famous and high-quality pig in a region as the research object, and the Internet of things technology runs through the whole industrial chain of pig from breeding, slaughtering, and processing, logistics, sales, and consumption. The data related to food safety in the industrial chain is transmitted to the database server through GPRS by the mobile terminal to the consumer for traceability query. At the same time, Establish multiple feedback mechanism of information, and provide data support for pig breeding by using the information of breeding and slaughtering process [15].

The whole industrial chain of pigs includes five links: breeding, breeding, slaughter division, logistics and sales, There are corresponding information management systems in each stage, which provide daily management for breeding plants, breeding plants, slaughterhouses, storage and logistics companies, and sales companies in different links, as well as write data to the database through the hardware collection terminal of the Internet of things, to provide data sources for the traceability of the whole industry chain. At the same time, to ensure the reliability and authenticity of the data source, the platform covers the supervision of the animal husbandry supervision department on the industrial chain information and the traceability query of consumers on the safety information related to meat products. Figure 2 shows the specific functions.

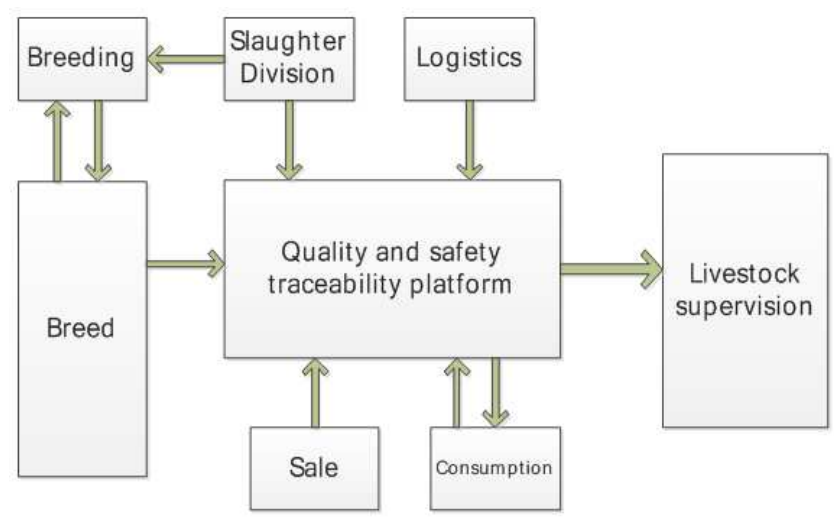

Figure 2. Function division of pig whole industry chain traceability.
The whole system adopts B / S architecture, which can be used through hardware platforms such as handheld devices and general PC, and is compatible with windows, Android, IOS and other operating systems, greatly facilitating the use of users, while reducing development costs and maintenance workload. After entering the information platform, They can directly input the traceability source code to query the traceability information of pigs [16].

The system is conducive to the real-time monitoring and control of the pig's growth environment by managers, convenient for consumers to query the information of all links from breeding to sales, and realize the tracking and traceability of pigs by consumers, governments and enterprises.

\section{Challenges in Implementing Iot in Rural Area}

The new central document proposes to build agricultural and rural big data centers and accelerate the application of modern information technology in the agricultural field, including the Internet of things, big data, and artificial intelligence [17].

The application of IoT in the field of agriculture is still in its infancy, and there are still some constraints and bottlenecks. The price of chips, processors, and other hardware equipment is high, the development of related software and application systems is relatively lagging, and the awareness and application level of grass-roots farmers on the Agricultural Internet of things need to be improved. It is not only limited to the Internet of things technology, accelerating the application of science and technology in agriculture should focus on the following aspects : Government guidance, policy support, increasing the interest of growers, encouraging market capital investment, Agricultural technology application demonstration, and improving the innovation enthusiasm of agricultural researchers. With the further implementation of the strategy of Rural Revitalization, the construction of modern agriculture and even smart agriculture is speeding up. Through improving the model of demonstration and guidance, strengthening the development and application training of software and hardware, the application of IoT in the field of agriculture will be increasingly extensive, effectively promoting the level of agricultural production and efficiency.

\section{References}

[1] https://news.cnhnb.com/rdzx/detail/121808/

[2] http://www.chinanews.com/gn/2015/05-26/7302562.shtml

[3] http://bhlc.sdau.edu.cn/pages/About/ptjs.jsp

[4] Liu Jun, et al. Design of a greenhouse environment monitoring system based on Internet of Things technology [J]. Journal of Chinese Agricultural Mechanization, 2016, 37 (12): 179 182. 
[5] Ge Wenjie, et al. State-of-the-art and Developing Strategies of Agricultural Internet of Things [J]. Transactions of the Chinese Society for Agricultural Machinery, 2014, 45 (7): 222 230, 277.

[6] Li Weiwei, et al. Construction of Intelligence agriculture production mode based on IoT cloud [J]. Journal of Chinese Agricultural Mechanization, 2016, 37 (2): 263 266.

[7] Liu Pingzeng. Application of agricultural big data platform in Intelligent Agriculture [J]. High-Technology and Industrialization. 2015, (5): 68-71.

[8] Zhang Wenxia, et al. Design and implementation of intelligent Agricultural greenhouse management system based on ZigBee wireless network [J]. Journal of Chinese Agricultural Mechanization, 2016, 37 (6): 247 250.

[9] Zheng JiYe et al. Agricultural IOT Architecture and Application Model Research [J]. Scientia Agricultura Sinica, 2017, 50 (4): 657 668.

[10] Wang maoli, et al. Research on digital farmland information monitoring system based on Internet of Things technology [J]. Journal of Chinese Agricultural Mechanization, 2019, 40 (9): 158 163, 180 .
[11] Vijayalakshmi \& Muruganand, Shanmugam. (2017). Different soft computing algorithms used in fire sensor node of wireless sensor network integrated with IoT. International Journal of Embedded Systems. 9. 310. 10.1504/IJES.2017.086125.

[12] Zhao xunming, et al. Advances in the application of RFID technology in food traceability systems [J]. FOOD \& MACHINERY, 2019, 36 (2): 212 215, 225.

[13] Chen Youqiao, et al. Tracing system of agricultural productions based on NFC [J]. Journal of Chinese Agricultural Mechanization, 2015, 36 (2): 145 149.

[14] Yang Liang. Preliminary Discussion on the Design of Coding Rules in Product Traceability of Beef Cattle [J]. Journal of Agricultural Science and Technology. 2015, 17 (1): 122-127.

[15] Zhang Yan, et al. Safety traceability platform building for the whole industry chain of Laiwu pig based on IOT [J]. Journal of Chinese Agricultural Mechanization, 2015, 36 (2): 141 144.

[16] Zhao luying, et al. Design of organic vegetable traceability system based on internet of things [J]. Jiangsu Agricultural Sciences, 2016, 44 (2): 427 430.

[17] http://news.idcquan.com/news/174765.shtml 